\title{
Usability and utility of eHealth for physical activity counselling in primary health care: a scoping review
}

\author{
Apichai Wattanapisit ${ }^{1,2^{*}}$ D, Titiporn Tuangratananon ${ }^{3}$ and Sanhapan Wattanapisit ${ }^{4}$
}

\begin{abstract}
Background: Physical activity (PA) counselling is an effective approach to promote PA in primary health care (PHC). Barriers to PA counselling in PHC include time constraints, lack of knowledge and skills of providers, and systemic barriers. Using electronic health (eHealth) has the potential to promote PA. This scoping review aimed to identify usability and utility of eHealth for tailored PA counselling introduced in PHC settings.

Methods: A scoping review included primary research articles. The authors systematically searched six databases (Cochrane Library, CINAHL Complete, Embase, PubMed, Scopus and Web of Science) from the inception of the databases. The search terms consisted of three search components: intervention (PA counselling), platform (eHealth), and setting (PHC). Additional articles were included through reference lists. The inclusion criteria were research or original articles with any study designs in adult participants.
\end{abstract}

Results: Of 2501 articles after duplicate removal, 2471 articles were excluded based on the title and abstract screening and full text review. A total of 30 articles were included for synthesis. The eHealth tools had a wide range of counselling domains as a stand-alone PA domain and multiple health behaviours. The included articles presented mixed findings of usability and utility of eHealth for PA counselling among patients and providers in PHC settings. Technical problems and the complexity of the programmes were highlighted as barriers to usability. The majority of articles reported effective utility, however, several articles stated unfavourable outcomes.

Conclusions: eHealth has the potential to support PA counselling in PHC. Facilitators and barriers to eHealth usability should be considered and adapted to particular settings and contexts. The utility of eHealth for promoting PA among patients should be based on the pragmatic basis to optimise resources.

Keywords: counselling, eHealth, physical activity, primary health care

\section{Background}

Physical activity (PA) is associated with several health benefits, including a reduction in risks of several medical conditions and premature mortality [1-3]. PA is one of the World Health Organization (WHO)'s important aspects in public health [4]. WHO has launched the Global Action

\footnotetext{
* Correspondence: apichai.wa@wu.ac.th

'School of Medicine, Walailak University, Thasala, Nakhon Si Thammarat, Thailand

Walailak University Hospital, Thasala, Nakhon Si Thammarat, Thailand Full list of author information is available at the end of the article
}

plan on Physical Activity (GAPPA) 2018-2030 to create: (i) active society; (ii) active environments; (iii) active people; and (iv) active systems [5]. Implementing and strengthening systems to increase PA and reduce sedentary behaviour (SB) in healthcare sectors is one of the 20 policy actions suggested in the GAPPA [5]. The suggested action in healthcare settings to promote $\mathrm{PA}$ is the counselling process embedded within healthcare facilities. According to the proposed action, characteristics and roles of primary health care (PHC) systems (e.g. 
comprehensiveness, coordination first contact, costeffectiveness) [6] are supposed to be a suitable setting for PA promotion $[7,8]$.

PA counselling is an approach to promote PA in PHC settings. PA counselling contains several processes: the assessment of current PA levels, advice on increasing PA; agreement to an individualised plan for PA; assistance in pertinent strategies to achieve PA goals; and arrangement for follow-ups $[8,9]$. A systematic review and meta-analysis revealed that PA counselling by primary care providers is an effective tool to modify patients' behaviours [10]. However, characteristics of PHC are diverse across countries, in terms of policies, resources, and strengths [11-13]. Implementing PA counselling in $\mathrm{PHC}$ is challenging. Barriers to PA counselling in PHC include time constraints, lack of knowledge and skills, and systemic barriers [14-17].

A study demonstrated that an electronic-based PA counselling system may be feasible for promoting PA among patients with chronic diseases [18]. Electronic health (eHealth), mobile health (mHealth), or electronicbased interventions have the potential to promote PA in PHC [19-21]. Although previous systematic reviews presented the effects of eHealth interventions on PA, they did not focus on PHC settings [22, 23]. To the best of our knowledge, using eHealth or electronic-based PA counselling systems in PHC and their outcomes vary in different PHC settings. The aim of this scoping review is to identify usability and utility of eHealth for tailored PA counselling introduced in PHC settings.

\section{Methods}

The authors conducted this scoping review following the PRISMA extension for scoping reviews (PRISMA-ScR) [24].

\section{Search methods}

The authors performed a systematic search in six databases: Cochrane Library, CINAHL Complete, Embase, PubMed, Scopus and Web of Science. The search included published articles from the inception of the databases to 16th January 2020. The search terms consisted of three search components: intervention (PA counselling), platform (eHealth), and setting (PHC). The search strategy is presented in Table 1. The filter function of each database was used to recruit articles published in English. All articles found from the databases were transferred to Endnote X4 citation manager (Thomson Reuters, Toronto, ON, Canada).

\section{Study selection}

After duplicate removal, two authors (AW and TT) independently screened titles and abstract. Disagreement about the title and abstract screening was reviewed by the third author (SW) and resolved through consensus. Subsequently, an author (AW) performed the full text review and included the eligible articles. Relevant articles were identified through reference lists and included as additional articles for reviews. The scoping review focused on usability and utility of electronic-based systems for PA counselling in PHC. The inclusion criteria were research or original articles with any study designs conducted in PHC settings and published in peer-reviewed journals. The exclusion criteria were studies conducted in paediatric populations and patients with specific diseases who required specialised care (e.g. cancers, chronic obstructive pulmonary disease, mental disorders). Review articles (i.e. systematic, scoping, narrative reviews), expert opinion excerpts, protocol articles, and trial registers were excluded. The included articles were discussed among the authors prior to data extraction and synthesis.

\section{Data extraction}

One author (AW) performed data extraction using the extraction form developed by the authors. Information from each eligible study included article title, name of first author, year of publication, country of study, study design, participant and setting, type of technology used, counselling domain, variable measurement, and outcomes. Another author (TT or SW) cross-checked the complete data extraction of each study.

\section{Methodological quality assessment}

Two authors (AW and SW) independently assessed the methodological quality of the included studies by using the Mixed Methods Appraisal Tool (MMAT) - Version $2018[25,26]$. The MMAT is a critical appraisal tool designed for reviews that included mixed types of studies [25]. Each included article was appraised by two screening questions. If the article passed the screening questions, the methodological quality criteria would be applied. The MMAT categorises study designs into five types: (i) qualitative; (ii) quantitative randomised controlled trials; (iii) quantitative nonrandomized; (iv) quantitative descriptive; and (v) mixed methods. Within each type, five items were assessed by dichotomous questions (yes/no or cannot tell). Therefore, the scoring system was $0-5$. For mixed methods studies, the assessment covered three types of study designs: (v) mixed methods; (i) qualitative; and either type of quantitative (ii) or (iii) or (iv), consequently, the scores were $0-15$ [25].

\section{Data synthesis}

Two authors (AW and either TT or SW) independently performed data synthesis based on the data extraction. The scope of usability included easiness and pleasantness of user interfaces of eHealth for PA counselling 
Table 1 Search terms

\begin{tabular}{ll}
\hline Search component & Search term \\
\hline Intervention & ("physical activity" OR "physical activities" OR "physically active" OR "physical exercise" OR exercise) \\
& AND \\
& (counselling OR counseling OR prescribing OR prescription OR advise OR advice OR educat*) \\
& (eHealth OR "electronic health" OR computer OR computer-based OR mobile OR device OR phone OR smartphone OR \\
"mobile phone" OR "cell phone" OR mHealth OR "mobile health" OR app OR application OR web OR website OR & web-based OR digital OR "digital health") \\
& ("primary care" OR "primary health care" OR "primary healthcare" OR "family practice" OR "family medicine" OR \\
Setting & "general practice" OR "general practitioner" OR GP) \\
&
\end{tabular}

[27]. The utility referred to a state that the eHealth for PA counselling provided user needs [27]. Based on the initial review of the included articles, the authors found that the outcomes of usability and utility varied across studies. For example, some studies asked a global rating scale (e.g. overall satisfaction) to rate the usability, while others divided usability into several aspects (e.g. easiness, appearance, support). To summarise the outcomes of each article, the key outcomes are presented in Additional file 2.

In addition, the authors identified three categories of the outcomes to quantify the variation among articles: (i) effective outcomes were noticeably addressed (or most aspects were rated $\geq 66.66 \%$ ); (ii) controversial or neutral outcomes were addressed (or most aspects were rated between 33.33 and 66.66\%); and (iii) ineffective outcomes were noticeably addressed (or most aspects were rated $\leq 33.33 \%$ ). For example, an article presented 'an average overall satisfaction greater than 3.3 out of 5' or 'more than $66.66 \%$ of participants satisfied', it would be considered 'effective'. If an article reported several aspects of usability or utility, the authors would consider each aspect and decided whether the majority of aspects scored: (i) $\geq 66.66 \%$ - effective; (ii) between 33.33 and $66.66 \%$ - controversial; or (iii) $\leq 33.33 \%$ - ineffective. A third author involved in consensus to resolve any ambiguous results in data synthesis.

\section{Results}

\section{Summary of search results and study selection}

The initial search in six databases obtained 3607 articles, and 1109 duplicates were removed. Of 2501 articles, 2436 articles were excluded based on reading titles and abstracts by two independent authors. A total of 65 fulltext articles were read, and 35 articles were excluded. The number of studies included in data synthesis was 30. Figure 1 presents the PRISMA flow diagram.

\section{Methodological quality assessment}

Of 30 articles, four articles were rated $100 \%$ of the items (5/5 items) related to methodological quality [28-31]. Four mixed methods studies were rated ranging from $66 \%(10 / 15$ items $)$ to over $80 \%$ (13/15 items) [18, $32-$
34]. The rest of the articles were rated $60 \%$ (3/5 items, $n=10)[20,35-43]$ or $80 \%(4 / 5$ items, $n=12)$ [21, 4454]. The MMAT scores are presented in Table 2 and Additional file 1.

\section{Counselling domains, eHealth used, and counselling processes}

Ten out of 30 articles focused on a stand-alone PA domain $[18,21,28,30,31,34,35,37-39]$. The rest of the articles embedded other components of health behaviours or counselling domains. Diet or nutrition was the most common element combined with PA. Some eHealth tools provided counselling about smoking, alcohol consumption, weight control, or the integration of multiple health behaviours (Additional file 2).

Based on the extraction of the included articles, the majority of eHealth PA counselling tools were computerbased technologies. An article published in 2002 presented the usage of telephone linked communication based on computer technology [45]. Of 17 articles published from 2014 to 2019 , more than half $(n=10)$ obviously presented the use of mobile technologies (e.g. smartphone, tablet) $[21,28,30,31,34,39,40,42,51,52]$, while some programmes were potential to access by mobile devices (Table 2 and Additional file 2) [20, 32].

Several eHealth tools presented in the included articles were published in combination with other articles. The two articles published in 2000 and 2002 illustrated the Patientcentred Assessment and Counseling for Exercise plus $\mathrm{Nu}$ trition (PACE+) [44, 45]. A tool developed in Sweden had been published in 2009 to 2011 [46-48]. Parekh et al. investigated the short-term and long-term effects of eHealth at 3 months and 12 months $[49,50]$. An intervention, SMART MOVE, conducted in Ireland were published in different occasions, including qualitative studies and a randomised controlled trial $[21,28,30]$. The research group in the Netherlands produced 'It's LiFe!' as an intervention for promoting PA in PHC [31, 34, 39]. The Spanish team introduced a randomised controlled trial to investigate the short- and long-term effects on utilisation of a mobile phone app [40, 42]. The online programme, MyPlan 1.0, developed in Belgium was presented in two articles (Table 2 and Additional file 2) [20,32]. 


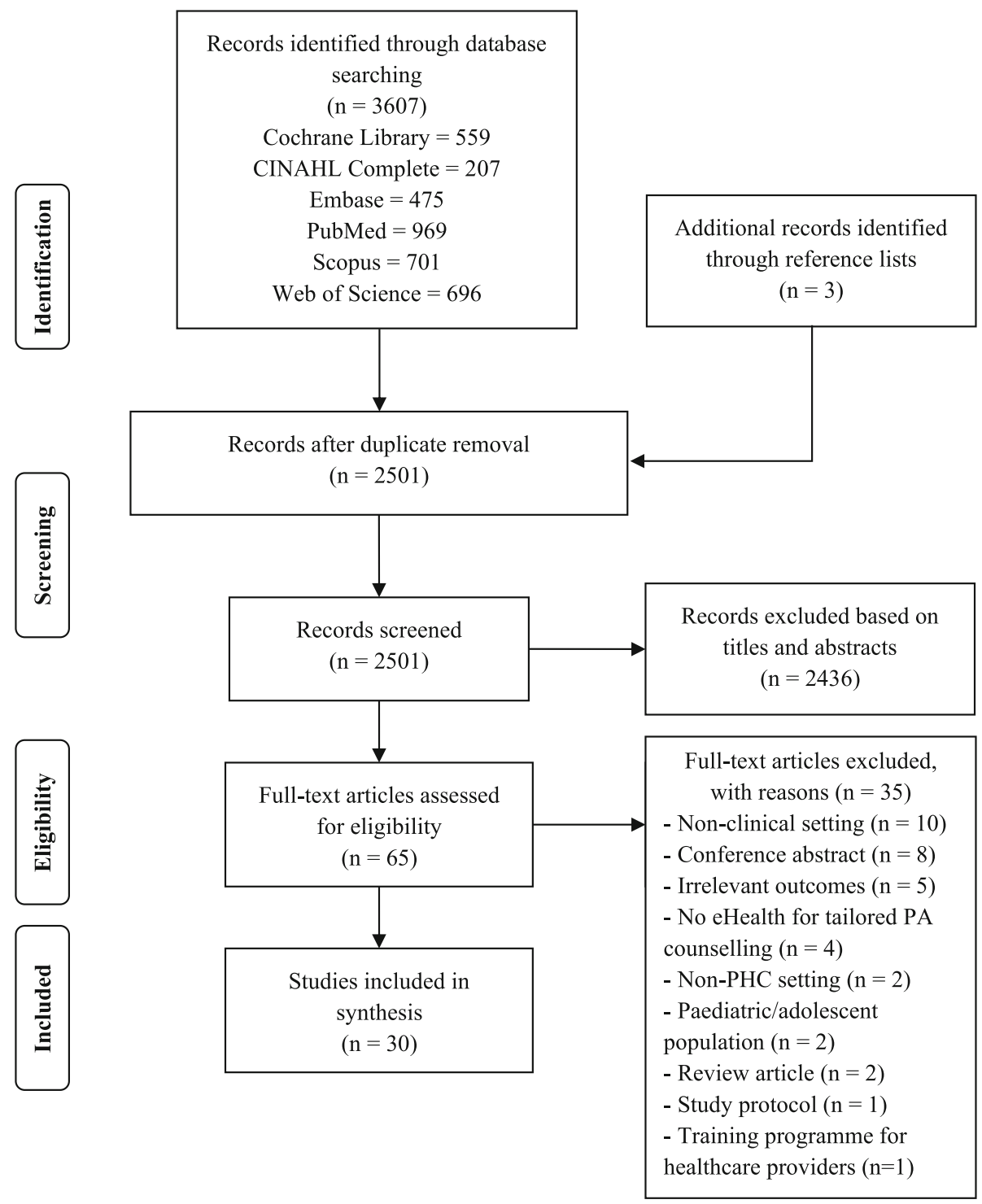

Fig. 1 PRISMA flow diagram of search process and results

With regard to the counselling processes, eHealth technologies were diversely utilised as PA counselling and promoting tools (Additional file 2). Some tools were designed for patients without any interactions with providers $[38,49,50]$. While some eHealth tools were used in a combination of multiple face-to-face consultations $[31,34,39]$. Some articles presented the use of a mobile app, as part of the intervention, to provide PA tracking and tailored feedback $[21,28,30]$.

\section{Usability and utility of eHealth for physical activity counselling}

The majority of articles highlighted the usability and/or utility of eHealth for PA counselling for patients or participants rather than PHC providers. In terms of studies investigated patients' outcomes, most articles (86.67\%, $n=26 / 30)$ investigated the utility of eHealth, while less than half $(43.33 \%, n=13 / 30)$ presented the usability. Providers' outcomes were presented as usability $(26.67 \%$, $n=8 / 30)$ and utility $(30.00 \%, n=9 / 30)$. The summary of the extraction and findings are shown in Table 2 and Additional file 2.

\section{Usability}

Patients' usability of eHealth was effective or positive in most articles $(61.54 \%, n=8 / 13)[34,35,38,39,44,46$, 52, 54]. Four articles $(30.77 \%)$ showed both satisfaction (e.g. easiness) and dissatisfaction in diverse factors (e.g. time consumption, phone battery consumption, technological issues) $[18,28,30,51]$. An article (7.69\%) 
Table 2 Summary of the outcomes of the physical activity domain

\begin{tabular}{|c|c|c|c|c|c|c|c|}
\hline \multirow{2}{*}{$\begin{array}{l}\text { Authors, year of } \\
\text { publication }\end{array}$} & \multirow{2}{*}{$\begin{array}{l}\text { MMAT } \\
\text { score }\end{array}$} & \multirow[t]{2}{*}{ Counselling domain } & \multirow[t]{2}{*}{ eHealth used } & \multicolumn{2}{|c|}{ Usability $^{\mathrm{a}}$} & \multicolumn{2}{|l|}{ Utility $^{a}$} \\
\hline & & & & Patients & Providers & Patients & Providers \\
\hline Prochaska et al. [44], 2000 & $4 / 5$ & PA and nutrition & PC and internet (web-based programme) & + & & + & + \\
\hline Calfas et al. [45], 2002 & $4 / 5$ & PA and nutrition & Computer programme & & + & + & + \\
\hline Pinto et al. [35], 2002 & $3 / 5$ & PA & TLC used computer technology & + & & + & \\
\hline Anhøj et al. [36], 2004 & $3 / 5$ & PA and diet & Internet based programme & - & - & - & - \\
\hline Sciamanna et al. [33], 2004 & $11 / 15^{b}$ & PA and smoking & Computer-tailored health communication & & - & & - \\
\hline Carlfjord et al. [46], 2009 & $4 / 5$ & PA and alcohol & Computer-based lifestyle intervention & + & & + & \\
\hline Carlfjord et al. [47], 2010 & $4 / 5$ & PA and alcohol & Computer-based lifestyle intervention & & \pm & & + \\
\hline Carroll et al. [37], 2010 & $3 / 5$ & PA & Computerised tailored report & & & \pm & \\
\hline Becker et al. [18], 2011 & $10 / 15^{b}$ & PA & Computer-based counselling system & \pm & & \pm & \\
\hline Christian et al. [29], 2011 & $5 / 5$ & PA and diet & Computer support programme & & & + & \\
\hline Leijon et al. [48], 2011 & $4 / 5$ & PA and alcohol & $\begin{array}{l}\text { Electronic screening and brief } \\
\text { intervention }\end{array}$ & & & + & \\
\hline De Coker et al. [38], 2012 & $3 / 5$ & PA & Computer-tailored website & + & & - & \\
\hline Parekh et al. [49], 2012 & $4 / 5$ & $\begin{array}{l}\text { PA, smoking, alcohol, } \\
\text { and diet }\end{array}$ & Personalised computer-tailored feedback & & & - & \\
\hline Casey et al. [28], 2014 & $5 / 5$ & PA & Smartphone app & \pm & & + & \\
\hline Glynn et al. [21], 2014 & $4 / 5$ & PA & Smartphone app & & & + & \\
\hline Parekh et al. [50], 2014 & $4 / 5$ & $\begin{array}{l}\text { PA, smoking, alcohol, } \\
\text { and diet }\end{array}$ & Personalised computer-tailored feedback & & & - & \\
\hline Verwey et al. [39], 2014 & $3 / 5$ & PA & $\begin{array}{l}\text { Iterative user-centered mobile technology } \\
\text { (smartphone, internet app, pedometer) }\end{array}$ & + & \pm & + & + \\
\hline $\begin{array}{l}\text { van der Weegen et al. [31], } \\
2015\end{array}$ & $5 / 5$ & PA & $\begin{array}{l}\text { Three-dimensional activity monitor, } \\
\text { mobile phone app, and web app }\end{array}$ & & & + & \\
\hline Choo et al. [51], 2016 & $4 / 5$ & $\begin{array}{l}\mathrm{PA} \text { and weight } \\
\text { reduction }\end{array}$ & Mobile app linked with an accelerometer & \pm & & + & \\
\hline Diaz et al. [52], 2016 & $4 / 5$ & $\begin{array}{l}\text { PA, nutrition, weight, } \\
\text { smoking, and alcohol }\end{array}$ & Tablet-based risk assessment programme & + & & - & \\
\hline Mann et al. [53], 2016 & $4 / 5$ & PA and diet & $\begin{array}{l}\text { Shared goal-setting tool embedded in } \\
\text { EMR }\end{array}$ & & & + & \\
\hline $\begin{array}{l}\text { Recio-Rodriguez et al. [40], } \\
2016\end{array}$ & $3 / 5$ & PA and diet & Mobile phone app & & & \pm & \\
\hline Verwey et al. [34], 2016 & $10 / 15^{b}$ & PA & $\begin{array}{l}\text { Iterative user-centered mobile technology } \\
\text { (smartphone, internet app, pedometer) }\end{array}$ & + & + & & \\
\hline Walters et al. [41], 2017 & $3 / 5$ & $\begin{array}{l}\text { Health and social risks } \\
\text { (included PA) }\end{array}$ & $\begin{array}{l}\text { Tailored computer-aided health and social } \\
\text { risk appraisal system }\end{array}$ & & & & \pm \\
\hline Degroote et al. [20], 2018 & $3 / 5$ & PA and nutrition & Website & & & + & \\
\hline Garcia-Ortiz et al. [42], 2018 & $3 / 5$ & PA and diet & Smartphone app & & & - & \\
\hline Glynn et al. [30], 2018 & $5 / 5$ & PA & Smartphone app & \pm & \pm & + & + \\
\hline Poppe et al. [32], 2018 & $13 / 15^{b}$ & PA and nutrition & Online programme & & \pm & - & \pm \\
\hline Abu-Saad et al. [54], 2019 & $4 / 5$ & PA and diet & Computer software & + & & - & \\
\hline Gill et al. [43], 2019 & $3 / 5$ & PA and diet & Customised health technology tools & & & + & \\
\hline
\end{tabular}

App application, EMR electronic medical record, MMAT Mixed Methods Appraisal Tool, PA physical activity, PC personal computer, TLC telephone linked communication

$a_{+}=$effective outcomes were noticeably addressed (or most aspects were rated $\geq 66.66 \%$ ). $\pm=$ controversial or neutral outcomes were addressed (or most aspects were rated between 33.33 and 66.66\%). - = ineffective outcomes were noticeably addressed (or most aspects were rated $\leq 33.33 \%$ ). The blanks refer to no outcome available

${ }^{b}$ mixed methods study 
published in 2004 noted that the internet based programme was complicated for patients [36].

Of eight articles investigated providers' usability, two articles (25.00\%) reported effective outcomes (e.g. high satisfaction) [34, 45]. Four articles (50.00\%) reported controversial outcomes (e.g. easiness vs technical issues) [30, 32, 39, 47]. Two articles (25.00\%) stated ineffective usability among PHC providers due to inexperienced staff, complications of the programme, and technical problems [33, 36].

\section{Utility}

A total of 26 articles reported utility aspects among patients. Fifteen articles (57.69\%) showed effective outcomes (e.g. improvement of PA participation, changes in knowledge, attitude, and goal setting) [20, 21, 28-31, 35, $39,43-46,48,51,53]$. Three articles (11.54\%) reported both significant and insignificant outcomes of different variables [18, 37, 40]. Eight articles (30.77\%) illustrated ineffective outcomes (e.g. no significant increase in PA levels) [32, 36, 38, 42, 49, 50, 52, 54].

Among nine articles indicated providers' utility, five articles $(55.56 \%)$ reported effective outcomes (e.g. usefulness of eHealth) [30, 39, 44, 45, 47]. Two articles (22.22\%) presented the feasibility of eHealth for PA counselling in PHC, however some barriers to implement the eHealth were addressed such as intervention costs $[32,41]$. The rest of the artilces $(22.22 \%, n=2)$ stated unfavourable outcomes such as technical errors of the programme, and time consuming $[33,36]$.

\section{Discussion}

\section{Summary}

This scoping review identified usability and utility of eHealth for tailored PA counselling in PHC. Thirty articles were included for analysis. The eHealth tools had a wide range of counselling domains as a stand-alone PA domain and multiple health behaviours. Computerbased technologies represented a dominant eHealth used for PA counselling and promotion in PHC. Mobile technologies (e.g. smartphone, tablet) had been favourable methods since 2014. The eHealth technologies were applied in different approaches with or without patientprovider interactions. The included articles presented mixed findings of usability and utility of eHealth for PA counselling among patients and providers in $\mathrm{PHC}$ settings.

Patients' usability of eHealth was effective or positive in most articles (61.54\%), controversial (30.77\%), and ineffective (7.69\%). In terms of providers' usability, relevant articles presented effective (25.00\%), controversial (50.00\%), and ineffective $(25.00 \%)$. Technical problems and the complexity of the programmes were highlighted as barriers to usability. The majority of articles reported effective utility, however, several articles stated unfavourable outcomes. According to the utility aspects among patients, the inconsistent findings were reported: effective (57.69\%); controversial (11.54\%); and ineffective $(30.77 \%)$. Provider's utility results were effective (55.56\%), controversial (22.22\%), and ineffective (22.22\%).

\section{Strengths and limitations}

There were some strengths of this scoping review. First, the systematic search was performed through six databases, which covered the major and specialised databases for systematic reviews [55]. Second, the scoping review focused on eHealth in PHC settings, which delivered a variety of services [56]. The specific focus could determine particular characteristics of eHealth for PA counselling in PHC settings. Third, the inclusion criteria did not limit study designs. Therefore, this increased yields on articles included and a wide range of findings.

Three major limitations were addressed. First, the scoping review analysed the findings of each article qualitatively. However, the authors considered the findings based on the consensus. Second, a meta-analysis was not performed for quantitative studies. The authors attempted to summarise the outcomes of each article by identifying the criteria to quantify the findings. Third, a diversity of outcome measurements and study designs affected the ability to identify the exact outcomes regarding usability and utility. This revealed the characteristics of scoping reviews, which mainly identified key characteristics related to the concept and knowledge gaps rather than investigating conflict results [57].

\section{Comparison with existing literature}

According to the findings of this scoping review, a variety of eHealth interventions were adopted for PA counselling. A review published in 2007 focused on the effects of eHealth interventions for PA and dietary behaviour change rather than the usability and utility [23]. A systematic review and meta-analysis of Kwan et al. demonstrated a diversity of eHealth strategies for promoting PA in older people and positive effects on time spent on PA, energy expenditure, and step counts [22]. Several eHealth technologies in this scoping review were in line with Kwan et al.'s findings (e.g. automated advice, tele-counselling, PA auto-tracking feedback), however, videogame interventions were not identified in this scoping review as previously mentioned in a systematic review [22].

eHealth interventions were also widely utilised and systematically reviewed for several health behaviours and conditions, such as smoking cessation, overweight, and obesity, which were common in PHC [58-60]. Aforementioned systematic reviews manifested the divergent findings. 
Nevertheless, their findings may shed light on effective approaches in PHC settings. Tailored interventions were more effective in supporting weight reduction and smoking cessation $[58,60]$. A systematic review of Hutchesson et al. presented that $40 \%$ of the included studies used more than one type of technologies [59], which were in line with some articles in our scoping review [31,34,39]. Multiple options used may help overwhelm barriers and improve the potency of healthcare-based interventions [61].

\section{Implications for research and practice}

The authors highlight two potential implications for future research. First, in this scoping review, reporting structures and outcome measurements are different among studies with various study designs. Therefore, it is challenging to synthesise and interpret the applicability and validity of each study. The standard reporting guidelines may be useful for eHealth studies to provide components for assessing the applicability and validity of the studies. For example, Baker et al. recommended the CONSORT Selected Criteria Adapted for eHealth randomised controlled trials [62]. The CONSORT-EHEA LTH (Consolidated Standards of Reporting Trials of Electronic and Mobile HEalth Applications and onLine TeleHealth) is also recommended for reporting eHealth randomised controlled trials [63]. Reporting guidelines for other study designs should be developed to enhance the quality and transparency of eHealth research. Second, future research should focus on the implementation of eHealth for PA counselling and promotion in PHC. Implementation research helps identify implementation challenges in real-world settings [64]. In addition, implementation research offers the understanding of indicators that contribute to the successful implementation, such as acceptability, adoption, appropriateness, cost, coverage, feasibility, fidelity, and sustainability [65].

In $\mathrm{PHC}$ practices, eHealth technologies are potential to support PA counselling. However, challenges of PA counselling and the use of eHealth in PHC are addressed. Time constraint is a key barrier to PA counselling in PHC $[14,15]$. This factor varies in healthcare settings. For example, a primary care physician consultation time could range from $48 \mathrm{~s}$ to $22.5 \mathrm{~min}$ [66]. An eHealth intervention should be designed for a specific setting. As a result, an eHealth intervention that consumes merely few minutes may suit a short consultation time space. Ones that required a longer period to participate in the eHealth technologies should be assigned in the waiting rooms or patient's homes. Moreover, recent technologies (e.g. mobile apps) can provide some clinical tasks with less support by PHC providers, especially, for health promoting tasks [67]. This may help optimise resources in PHC settings. In addition, technical issues are noted in this scoping review. A user-friendly tool for patients and providers should be considered to overcome the technical difficulties. Implementing an eHealth system should take into account of several factors such as appropriateness (e.g. complexity, adaptability, compatibility with existing systems and practices, cost, safety, evidence-based components, quality), provision of training and education, and key stakeholders $[68,69]$.

\section{Conclusions}

This scoping review found mixed findings in terms of usability and utility of eHealth for PA counselling among patients and providers in PHC settings. Barriers to eHealth usability (e.g. technical issues) should be considered and adapted to a particular PHC setting. The use of eHealth interventions for promoting PA among patients should be pragmatic in order to optimise resources.

\section{Supplementary Information}

The online version contains supplementary material available at https://doi. org/10.1186/s12875-020-01304-9.

Additional file 1. Summary of methodological assessment

Additional file 2. Summary of the included studies

\section{Abbreviations}

eHealth: Electronic health; PA: Physical activity; PHC: Primary health care

\section{Acknowledgements}

The authors wish to thank Aekthawat Watthanachon and the new strategic research (P2P) project, Walailak University for their support.

\section{Authors' contributions}

AW, TT, and SW initiated and developed the review strategy. AW and TT performed searches and screenings. AW, TT, and SW contributed to data synthesis. AW wrote the first draft of the manuscript. All authors approved the final draft of the manuscript.

\section{Funding}

This scoping review was part of a research project funded by Medical Association of Thailand. The funding body had no role in the design, execution, interpretation, or writing of the study.

Availability of data and materials

All data analysed during this study are included in this published article and its additional files.

Ethics approval and consent to participate Not applicable.

Consent for publication

Not applicable.

\section{Competing interests}

The authors declare no potential competing interests.

\section{Author details}

'School of Medicine, Walailak University, Thasala, Nakhon Si Thammarat, Thailand. 'Walailak University Hospital, Thasala, Nakhon Si Thammarat, Thailand. ${ }^{3}$ International Health Policy Program, Ministry of Public Health, Muang, Nonthaburi, Thailand. ${ }^{4} T$ hasala Hospital, Thasala, Nakhon Si Thammarat, Thailand. 
Received: 18 June 2020 Accepted: 29 October 2020 Published online: 06 November 2020

\section{References}

1. Kyu HH, Bachman VF, Alexander LT, Mumford JE, Afshin A, Estep K, et al. Physical activity and risk of breast cancer, colon cancer, diabetes, ischemic heart disease, and ischemic stroke events: systematic review and doseresponse meta-analysis for the Global Burden of Disease Study 2013. BMJ. 2016:354:i3857.

2. Reiner M, Niermann C, Jekauc D, Woll A. Long-term health benefits of physical activity--A systematic review of longitudinal studies. BMC Public Health. 2013;13:813.

3. Warburton DER, Bredin SSD. Health benefits of physical activity: A systematic review of current systematic reviews. Curr Opin Cardiol. 2017; 32(5):541-56.

4. Tuangratananon T, Wangmo S, Widanapathirana N, Pongutta S, Viriyathorn S, Patcharanarumol W, et al. Implementation of national action plans on noncommunicable diseases, Bhutan, Cambodia, Indonesia, Philippines, Sri Lanka, Thailand and Viet Nam. Bull World Health Organ. 2019;97(2):129-41.

5. World Health Organization. Global action plan on physical activity 20182030: more active people for a healthier world. Geneva: World Health Organization; 2018.

6. Kroenke K. The many C's of primary care. J Gen Intern Med. 2004;19(6): 708-9.

7. Lion A, Vuillemin A, Thornton JS, Theisen D, Stranges S, Ward M. Physical activity promotion in primary care: A Utopian quest? Health Promot Int. 2019;34(4):877-86.

8. Shuval K, Leonard T, Drope J, Katz DL, Patel AV, Maitin-Shepard M, et al. Physical activity counseling in primary care: Insights from public health and behavioral economics. CA Cancer J Clin. 2017;67(3):233-44.

9. Aittasalo M, Kukkonen-Harjula K, Toropainen E, Rinne M, Tokola K, Vasankari T. Developing physical activity counselling in primary care through participatory action approach. BMC Fam Pract. 2016;17(1):141.

10. Orrow G, Kinmonth A-L, Sanderson S, Sutton S. Effectiveness of physical activity promotion based in primary care: Systematic review and metaanalysis of randomised controlled trials. BMJ. 2012;344:e1389.

11. Bitton A, Ratcliffe HL, Veillard JH, Kress DH, Barkley S, Kimball M, et al. Primary health care as a foundation for strengthening health systems in low- and middle-income countries. J Gen Intern Med. 2017;32(5):566-71.

12. Kassai R, van Weel C, Flegg K, Tong SF, Han TM, Noknoy S, et al. Priorities for primary health care policy implementation: recommendations from the combined experience of six countries in the Asia-Pacific. Aust J Prim Health. 2020. https://doi.org/10.1071/PY19194.

13. Pavlič DR, Sever M, Klemenc-Ketiš Z, Švab I, Vainieri M, Seghieri C, et al. Strength of primary care service delivery: a comparative study of European countries, Australia, New Zealand, and Canada. Prim Health Care Res Dev. 2018;19(3):277-87.

14. Wattanapisit $\mathrm{A}$, Thanamee $\mathrm{S}$, Wongsiri S. Physical activity counselling among GPs: A qualitative study from Thailand. BMC Fam Pract. 2019;20(1):72.

15. Hebert ET, Caughy MO, Shuval K. Primary care providers' perceptions of physical activity counselling in a clinical setting: A systematic review. $\mathrm{Br} J$ Sports Med. 2012:46(9):625-31.

16. Omura JD, Bellissimo MP, Watson KB, Loustalot F, Fulton JE, Carlson SA. Primary care providers' physical activity counseling and referral practices and barriers for cardiovascular disease prevention. Prev Med. 2018;108: $115-22$.

17. Wattanapisit A, Wattanapisit S, Wongsiri S. Overview of physical activity counseling in primary care. J Korean Fam Med. 2020. https://doi.org/10. 4082/kjfm.19.0113.

18. Becker A, Herzberg D, Marsden N, Thomanek S, Jung H, Leonhardt C. A new computer-based counselling system for the promotion of physical activity in patients with chronic diseases-results from a pilot study. Patient Educ Couns. 2011:83(2):195-202

19. Yerrakalva D, Yerrakalva D, Hajna S, Griffin S. Effects of mobile health app interventions on sedentary time, physical activity, and fitness in older adults: Systematic review and meta-analysis. J Med Internet Res. 2019;21(11): e14343.

20. Degroote L, Plaete J, De Bourdeaudhuij I, Verloigne M, Van Stappen V, De Meester $A$, et al. The effect of the eHealth intervention 'MyPlan 1.0' on physical activity in adults who visit general practice: A quasi-experimental trial. Int J Environ Res Public Health. 2018;15(2):228.
21. Glynn LG, Hayes PS, Casey M, Glynn F, Alvarez-Iglesias A, Newell J, et al. Effectiveness of a smartphone application to promote physical activity in primary care: The SMART MOVE randomised controlled trial. Br J Gen Pract. 2014;64(624):e384-91.

22. Kwan RYC, Salihu D, Lee PH, Tse M, Cheung DSK, Roopsawang I, et al. The effect of e-health interventions promoting physical activity in older people: A systematic review and meta-analysis. Eur Rev Aging Phys Act. 2020;17(1):7.

23. Norman GJ, Zabinski MF, Adams MA, Rosenberg DE, Yaroch AL, Atienza AA. A review of eHealth interventions for physical activity and dietary behavior change. Am J Prev Med. 2007;33(4):336-45.

24. Tricco AC, Lillie E, Zarin W, O'Brien KK, Colquhoun $H$, Levac D, et al. PRISMA Extension for Scoping Reviews (PRISMA-ScR): Checklist and explanation. Ann Intern Med. 2018;169(7):467-73.

25. Hong QN, Pluye P, Fàbregues S, Bartlett G, Boardman F, Cargo M, et al. Mixed Methods Appraisal Tool (MMAT), version 2018: Canadian Intellectual Property Office, Industry Canada. http://mixedmethodsappraisaltoolpublic. pbworks.com/w/file/fetch/127916259/MMA. 390 T_2018_criteria-manual_ 2018-08-01_ENG.pdf. Accessed 30 Mar 2020.

26. Hong QN, Pluye P, Fàbregues $\mathrm{S}$, Bartlett G, Boardman F, Cargo M, et al. Improving the content validity of the mixed methods appraisal tool: a modified e-Delphi study. J Clin Epidemiol. 2019;111:49-59.

27. Sousa VEC, Dunn LK. Towards usable e-health. A systematic review of usability questionnaires. Appl Clin Inform. Appl Clin Inform. 2017;8(2): $470-90$

28. Casey M, Hayes PS, Glynn F. G OL, Heaney D, Murphy AW, et al. Patients' experiences of using a smartphone application to increase physical activity: The SMART MOVE qualitative study in primary care. Br J Gen Pract. 2014; 64(625):e500-8.

29. Christian JG, Byers TE, Christian KK, Goldstein MG, Bock BC, Prioreschi B, et al. A computer support program that helps clinicians provide patients with metabolic syndrome tailored counseling to promote weight loss. J Am Diet Assoc 2011;111(1):75-83.

30. Glynn LG, Glynn F, Casey M, Wilkinson LG, Hayes PS, Heaney D, et al. Implementation of the SMART MOVE intervention in primary care: a qualitative study using normalisation process theory. BMC Fam Pract. 2018;19(1):48.

31. van der Weegen $S$, Verwey $R$, Spreeuwenberg $M$, et al. It's LiFe! mobile and web-based monitoring and feedback tool embedded in primary care increases physical activity: A cluster randomized controlled trial. J Med Internet Res. 2015;17(7):e184.

32. Poppe L, Plaete J, Huys N, Verloigne M, Deveugele M, De Bourdeaudhuii I, et al. Process evaluation of an eHealth intervention implemented into general practice: General practitioners' and patients' views. Int J Environ Res Public Health. 2018:15(7):1475.

33. Sciamanna CN, Marcus BH, Goldstein MG, Lawrence K, Swartz S, Bock B, et al. Feasibility of incorporating computer-tailored health behaviour communications in primary care settings. Inform Prim Care. 2004;12(1):40-8.

34. Verwey $\mathrm{R}$, van der Weegen $\mathrm{S}$, Spreeuwenberg $\mathrm{M}$, Tange $\mathrm{H}$, van der Weijden $T$, de Witte L. Process evaluation of physical activity counselling with and without the use of mobile technology: A mixed methods study. Int J Nurs Stud. 2016;53:3-16.

35. Pinto BM, Friedman R, Marcus BH, Kelley H, Tennstedt S, Gillman MW. Effects of a computer-based, telephone-counseling system on physical activity. Am J Prev Med. 2002;23(2):113-20.

36. Anhøj J, Jensen AH. Using the internet for life style changes in diet and physical activity: A feasibility study. J Med Internet Res. 2004;6(3):e28.

37. Carroll JK, Lewis BA, Marcus BH, et al. Computerized tailored physical activity reports: A randomized controlled trial. Am J Prev Med. 2010;39(2):148-56.

38. De Cocker K, Spittaels H, Cardon G, De Bourdeaudhuij I, Vandelanotte C, De Cocker K, et al. Web-based, computer-tailored, pedometer-based physical activity advice: Development, dissemination through general practice, acceptability, and preliminary efficacy in a randomized controlled trial. J Med Internet Res. 2012;14(2):e53.

39. Verwey $R$, van der Weegen $S$, Spreeuwenberg M, Tange $H$, van der Weijden $T$, de Witte L. Technology combined with a counseling protocol to stimulate physical activity of chronically ill patients in primary care. Stud Health Technol Inform. 2014;201:264-70.

40. Recio-Rodriguez Jl, Agudo-Conde C, Martin-Cantera C, González-Viejo M, Fernandez-Alonso MC, Arietaleanizbeaskoa MS, et al. Short-term effectiveness of a mobile phone app for increasing physical activity and adherence to the mediterranean diet in primary care: A randomized controlled trial (EVIDENT II study). J Med Internet Res. 2016;18(12):e331. 
41. Walters K, Kharicha K, Goodman C, Handley M, Manthorpe J, Cattan M, et al. Promoting independence, health and wellbeing for older people: a feasibility study of computer-aided health and social risk appraisal system in primary care. BMC Fam Pract. 2017;18(1):47.

42. Garcia-Ortiz L, Recio-Rodriguez Jl, Agudo-Conde C, Patino-Alonso MC, Maderuelo-Fernandez JA, Gento IR, et al. Long-term effectiveness of a smartphone app for improving healthy lifestyles in general population in primary care: Randomized controlled trial (Evident II ki study). JMIR mHealth uHealth. 2018;6(4):e107.

43. Gill DP, Blunt W, Silva N, Stiller-Moldovan C, Zou GY, Petrella RJ. The HealtheSteps (TM) lifestyle prescription program to improve physical activity and modifiable risk factors for chronic disease: A pragmatic randomized controlled trial. BMC Public Health. 2019:19(1):841.

44. Prochaska JJ, Zabinski MF, Calfas KJ, Sallis JF, Patrick K. PACE+: Interactive communication technology for behavior change in clinical settings. Am J Prev Med. 2000;19(2):127-31.

45. Calfas KJ, Sallis JF, Zabinski MF, Wilfley DE, Rupp J, Prochaska JJ, et al. Preliminary evaluation of a multicomponent program for nutrition and physical activity change in primary care: PACE+ for adults. Prev Med. 2002; 34(2):153-61.

46. Carlfjord S, Nilsen P, Leijon M, Andersson A, Johansson K, Bendtsen P. Computerized lifestyle intervention in routine primary health care: Evaluation of usage on provider and responder levels. Patient Educ Couns. 2009;75(2):238-43.

47. Carlfjord S, Johansson K, Bendtsen P, Nilsen P, Andersson A. Staff perspectives on the use of a computer-based concept for lifestyle intervention implemented in primary health care. Health Educ J. 2010;69(3): 246-56.

48. Leijon M, Arvidsson D, Nilsen P, Ekman DS, Carlfjord S, Andersson A, et al. Improvement of physical activity by a kiosk-based electronic screening and brief intervention in routine primary health care: Patient-initiated versus staff-referred. J Med Internet Res. 2011;13(4):e99.

49. Parekh S, Vandelanotte C, King D, Boyle FM. Improving diet, physical activity and other lifestyle behaviours using computer-tailored advice in general practice: A randomised controlled trial. Int J Behav Nutr Phys Act. 2012;9(1):108

50. Parekh S, King D, Boyle FM, Vandelanotte C. Randomized controlled trial of a computer-tailored multiple health behaviour intervention in general practice: 12-month follow-up results. Int J Behav Nutr Phys Act. 2014;11(1):41.

51. Choo S, Kim JY, Jung SY, Kim S, Kim JE, Han JS, et al. Development of a weight loss mobile app linked with an accelerometer for use in the clinic: Usability, acceptability, and early testing of its impact on the patient-doctor relationship. JMIR mHealth uHealth. 2016;4(1):e24.

52. Diaz VA, Mainous AG 3rd, Gavin JK, Player MS, Wright RU Jr. Use of a tabletbased risk assessment program to improve health counseling and patientprovider relationships in a federally qualified health center. Am J Med Qual. 2016;31(5):434-40.

53. Mann DM, Palmisano J, Lin JJ. A pilot randomized trial of technologyassisted goal setting to improve physical activity among primary care patients with prediabetes. Prev Med Rep. 2016:4:107-12.

54. Abu-Saad K, Murad H, Barid R, Olmer L, Ziv A, Younis-Zeidan N, et al. Development and efficacy of an electronic, culturally adapted lifestyle counseling tool for improving diabetes-related dietary knowledge: Randomized controlled trial among ethnic minority adults with type 2 diabetes mellitus. J Med Internet Res. 2019;21(10):e13674.

55. Bramer WM, Rethlefsen ML, Kleijnen J, Franco OH. Optimal database combinations for literature searches in systematic reviews: A prospective exploratory study. Syst Rev. 2017;6(1):245.

56. Starfield B, Shi L, Macinko J. Contribution of primary care to health systems and health. Milbank Q. 2005;83(3):457-502.

57. Munn Z, Peters MDJ, Stern C, Tufanaru C, McArthur A, Aromataris E. Systematic review or scoping review? Guidance for authors when choosing between a systematic or scoping review approach. BMC Med Res Methodol. 2018;18(1):143

58. Do HP, Tran BX, Le Pham Q, Nguyen LH, Tran TT, Latkin CA, et al. Which eHealth interventions are most effective for smoking cessation? A systematic review. Patient Prefer Adherence. 2018;12:2065-84.

59. Hutchesson MJ, Rollo ME, Krukowski R, Ells L, Harvey J, Morgan PJ, et al. eHealth interventions for the prevention and treatment of overweight and obesity in adults: a systematic review with meta-analysis. Obes Rev. 2015; 16(5):376-92.
60. Ryan K, Dockray S, Linehan C. A systematic review of tailored eHealth interventions for weight loss. Digit Health. 2019;5:2055207619826685.

61. Tate DF, Lyons EJ, Valle CG. High-tech tools for exercise motivation: use and role of technologies such as the internet, mobile applications, social media, and video games. Diabetes Spectr. 2015;28(1):45-54.

62. Baker TB, Gustafson DH, Shaw B, Hawkins R, Pingree S, Roberts $L$, et al. Relevance of CONSORT reporting criteria for research on eHealth interventions. Patient Educ Couns. 2010;81(Suppl):S77-86.

63. Eysenbach G. CONSORT-EHEALTH: Improving and Standardizing Evaluation Reports of Web-based and Mobile Health Interventions. J Med Internet Res. 2011;13(4):e126.

64. Theobald S, Brandes N, Gyapong M, El-Saharty S, Proctor E, Diaz T, et al. Implementation research: new imperatives and opportunities in global health. Lancet. 2018;392(10160):2214-28.

65. Peters DH, Adam T, Alonge O, Agyepong IA, Tran N. Implementation research: What it is and how to do it. BMJ. 2013;347:f6753.

66. Irving G, Neves AL, Dambha-Miller H, Oishi A, Tagashira H, Verho A, et al. International variations in primary care physician consultation time: A systematic review of 67 countries. BMJ Open. 2017;7(10):e017902.

67. Wattanapisit A, Teo CH, Wattanapisit S, Teoh E, Woo WJ, Ng CJ. Can mobile health apps replace GPs? A scoping review of comparisons between mobile apps and GP tasks. BMC Med Inform Decis Mak. 2020;20(1):5.

68. Ross J, Stevenson F, Lau R, Murray E. Factors that influence the implementation of e-health: A systematic review of systematic reviews (an update). Implement Sci. 2016;11(1):146.

69. van der Kleij RMJJ, Kasteleyn MJ, Meijer E, Bonten TN, Houwink EJF, Teichert M, et al. SERIES: eHealth in primary care. Part 1: Concepts, conditions and challenges. Eur J Gen Pract. 2019;25(4):179-89.

\section{Publisher's Note}

Springer Nature remains neutral with regard to jurisdictional claims in published maps and institutional affiliations.

Ready to submit your research? Choose BMC and benefit from:

- fast, convenient online submission

- thorough peer review by experienced researchers in your field

- rapid publication on acceptance

- support for research data, including large and complex data types

- gold Open Access which fosters wider collaboration and increased citations

- maximum visibility for your research: over $100 \mathrm{M}$ website views per year

At BMC, research is always in progress.

Learn more biomedcentral.com/submissions 